\title{
Long-Term Safety of Growth Hormone Treatment in Childhood: Two Large Observational Studies: NordiNet IOS and ANSWER.
}

\author{
Lars Sävendahl \\ Karolinska Institutet, Karolinska University Hospital, Solna, Sweden \\ Michel Polak \\ Université de Paris, Hôpital Universitaire Necker Enfants Malades, Paris, France \\ Philippe Backeljauw \\ Cincinnati Children's Hospital Medical Center, University of Cincinnati College of Medicine, Cincinnati, \\ Ohio, USA \\ Joanne C Blair

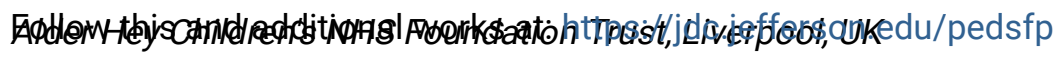 \\ Diadert of thalerediatrics Commons

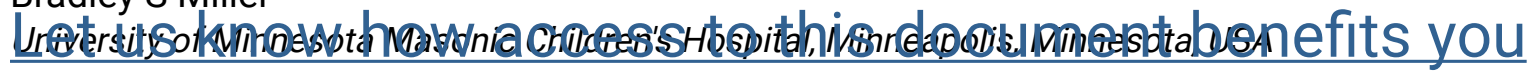

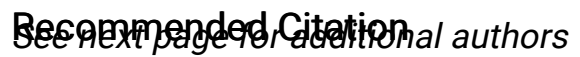

Sävendahl, Lars; Polak, Michel; Backeljauw, Philippe; Blair, Joanne C; Miller, Bradley S; Rohrer,

Tilman R; Hokken-Koelega, Anita; Pietropoli, Alberto; Kelepouris, Nicky; and Ross, Judith L., "Long-Term Safety of Growth Hormone Treatment in Childhood: Two Large Observational Studies: NordiNet IOS and ANSWER." (2021). Department of Pediatrics Faculty Papers. Paper 103.

https://jdc.jefferson.edu/pedsfp/103

This Article is brought to you for free and open access by the Jefferson Digital Commons. The Jefferson Digital Commons is a service of Thomas Jefferson University's Center for Teaching and Learning (CTL). The Commons is a showcase for Jefferson books and journals, peer-reviewed scholarly publications, unique historical collections from the University archives, and teaching tools. The Jefferson Digital Commons allows researchers and interested readers anywhere in the world to learn about and keep up to date with Jefferson scholarship. This article has been accepted for inclusion in Department of Pediatrics Faculty Papers by an authorized administrator of the Jefferson Digital Commons. For more information, please contact: JeffersonDigitalCommons@jefferson.edu. 


\section{Authors}

Lars Sävendahl, Michel Polak, Philippe Backeljauw, Joanne C Blair, Bradley S Miller, Tilman R Rohrer, Anita Hokken-Koelega, Alberto Pietropoli, Nicky Kelepouris, and Judith L. Ross 


\title{
Long-Term Safety of Growth Hormone Treatment in Childhood: Two Large Observational Studies: NordiNet IOS and ANSWER
}

\section{Lars Sävendahl,, ${ }^{1}$ Michel Polak, ${ }^{2}$ Philippe Backeljauw, ${ }^{3}$ Joanne C. Blair, ${ }^{4}$ Bradley S. Miller, ${ }^{5}$ Tilman R. Rohrer, ${ }^{6}$ Anita Hokken-Koelega, ${ }^{7}$ Alberto Pietropoli, ${ }^{8}$ Nicky Kelepouris, ${ }^{9}$ and Judith Ross ${ }^{10,11}$}

\begin{abstract}
${ }^{1}$ Karolinska Institutet, Karolinska University Hospital, SE-171 64 Solna, Sweden; ${ }^{2}$ Université de Paris, Hôpital Universitaire Necker Enfants Malades, 75015 Paris, France; ${ }^{3}$ Cincinnati Children's Hospital Medical Center, University of Cincinnati College of Medicine, Cincinnati, Ohio 45229, USA; ${ }^{4}$ Alder Hey Children's NHS Foundation Trust, Liverpool L12 2AP, UK; ${ }^{5}$ University of Minnesota Masonic Children's Hospital, Minneapolis, Minnesota 55454, USA; ${ }^{6}$ University Children's Hospital, Saarland University Medical Center, 66421 Homburg, Germany; ${ }^{7}$ Department of Pediatrics, Division of Endocrinology, Erasmus University Medical Center/Sophia Children's Hospital, 3015 CN Rotterdam, the Netherlands; ${ }^{8}$ Novo Nordisk Health Care AG, 8050Zurich, Switzerland; ${ }^{9}$ Novo Nordisk Inc, Plainsboro, New Jersey 08536, USA; ${ }^{10}$ Thomas Jefferson University, Philadelphia, Pennsylvania 19107, USA; and ${ }^{11}$ Nemours/DuPont Hospital for Children, Wilmington, Delaware 19803, USA
\end{abstract}

ORCiD number: 0000-0003-1067-4976 (L. Sävendahl).

\begin{abstract}
Abbreviations: ADR, adverse drug reaction; AE, adverse event; ANSWER, American Norditropin Studies: Web-Enabled Research; GH, growth hormone; GHD, growth hormone deficiency; ICP, intracranial pressure; NordiNet IOS, NordiNet International Outcome Study; SADR, serious adverse drug reaction; SAGhE, Safety and Appropriateness of Growth hormone treatments in Europe; SCFE, slipped capital femoral epiphysis; SGA, small for gestational age; SOC, system organ class.
\end{abstract}

Received: 16 December 2020; Editorial Decision: 1 February 2021; First Published Online: 11 February 2021; Corrected and Typeset: 13 April 2021.

\section{Abstract}

Context: Growth hormone (GH) treatment has a generally good safety profile; however, concerns about increased mortality risk in adulthood have been raised.

Objective: This work aims to assess the long-term safety of GH treatment in clinical practice.

Methods: Data were collected from 676 clinics participating in 2 multicenter longitudinal observational studies: the NordiNet International Outcome Study (2006-2016, Europe) and ANSWER Program (2002-2016, USA). Pediatric patients treated with GH were classified into 3 risk groups based on diagnosis. Intervention consisted of daily $\mathrm{GH}$ treatment, and main outcome measures included incidence rates (events/1000 patientyears) of adverse drug reactions (ADRs), serious adverse events (SAEs), and serious ADRs, and their relationship to GH dose.

Results: The combined studies comprised 37702 patients $168.4 \%$ in low-risk, $27.5 \%$ in intermediate-risk, and $4.1 \%$ in high-risk groups) and 130476 patient-years of exposure. The low-risk group included children born small for gestational age (SGA; 20.7\%) and

ISSN Print 0021-972X 
non-SGA children (eg, with GH deficiency; 79.3\%). Average GH dose up to the first adverse event $(A E)$ decreased with increasing risk category. Patients without $A E s$ received higher average $\mathrm{GH}$ doses than patients with more than one $\mathrm{AE}$ across all groups. A significant inverse relationship with $\mathrm{GH}$ dose was shown for ADR and SAE incidence rates in the low-risk group $(P=.003$ and $P=.001$, respectively) and the non-SGA subgroup (both $P=.002)$, and for SAEs in the intermediate- and high-risk groups $(P=.002$ and $P=.05$, respectively).

Conclusions: We observed no indication of increased mortality risk nor AE incidence related to $\mathrm{GH}$ dose in any risk group. A short visual summary of our work is available (1).

Key Words: adverse events, childhood, human growth hormone, long-term safety, neoplasms and malignancies, SAGhE

Treatment with recombinant human growth hormone $(\mathrm{GH})$ is used widely in children with growth failure to improve linear growth and with the aim of achieving normal adult height. Treatment with GH has been approved for a variety of indications, including GH deficiency (GHD), short stature in children born small for gestational age (SGA), chronic kidney disease, Turner syndrome, Noonan syndrome, and Prader-Willi syndrome. In the United States, it has also been approved for idiopathic short stature.

Long-term effectiveness and safety of GH treatment in clinical practice has been demonstrated in several longitudinal observational studies (2-11). However, concerns were raised following the preliminary French retrospective study "Safety and Appropriateness of Growth hormone treatments in Europe" (SAGhE) regarding an increase in adult mortality following GH treatment in childhood, in patients categorized a priori into a low-mortality risk group $(\mathrm{n}=6928)(12)$. The risk appeared the highest in patients who received $\mathrm{GH}$ doses greater than $50 \mu \mathrm{g} / \mathrm{kg} / \mathrm{day}$, for whom the incidence of bone tumors and cerebral hemorrhage increased $(12,13)$. In another preliminary SAGhE study from Belgium, the Netherlands, and Sweden, in the low-risk group $(\mathrm{n}=2543)$ the majority of deaths $(76 \%$; 16/21) were caused by accidents and suicides, and patients did not die of cardiovascular disease or cancer (14). Lastly, in a recent report from the full SAGhE consortium (Belgium, France, Germany, Italy, the Netherlands, Sweden, Switzerland, and the United Kingdom), with up to 25 years of follow-up and 24232 patients categorized into 3 risk groups, it was reported that, while some cause-specific mortality from circulatory and hematological diseases was increased in all groups, the mortality was not associated with GH doses in any risk group (15).

We address the long-term safety of $\mathrm{GH}$ treatment in pediatric patients by evaluating data from 2 complementary noninterventional studies with a common design: the NordiNet International Outcome Study (IOS) and the
American Norditropin Studies: Web-Enabled Research (ANSWER) Program. Interim results from NordiNet IOS have previously been published, after evaluating safety data from 13834 patients categorized into groups by mortality risk and stratified by average GH dose (16). No safety signals were observed, and no association between GH dose and the incidence of adverse events (AEs) was found (16).

In this paper, we report a combined analysis from the NordiNet IOS and the ANSWER Program, evaluating the entire safety data set from more than 37000 patients from 23 countries, with up to 10 years of follow-up (17). We evaluated the frequency and incidence rates of serious (SAEs) and/or treatment-related AEs reported during GH treatment in pediatric patients enrolled in the NordiNet IOS and ANSWER Program, who were classified into 3 risk groups based on their diagnosis as per the SAGhE cohort study categorization. We also investigated the effect of GH dose on the incidence rates of AEs and report details on events of special medical interest.

\section{Materials and Methods}

\section{Study Design and Ethics}

The NordiNet IOS (NCT00960128) and ANSWER Program (NCT01009905) were noninterventional, multicenter registry studies monitoring the long-term outcomes of GH treatment (with Norditropin; Novo Nordisk A/S) in children and adults, in real-world clinical practice. The NordiNet IOS was ongoing between April 2006 and December 2016 and involved 469 clinics in 22 countries throughout Europe and the Middle East; the ANSWER Program took place from June 2002 to September 2016 in 207 clinics in the United States. The designs of both studies have previously been reported in detail $(17,18)$.

The 2 studies were complementary, with similar aims and using the same data management electronic platform. 
Minor differences in study design have been described elsewhere (17). Both studies were conducted with approval from relevant ethics committees, written consent from patients, and pseudonymization of all data in accordance with the Declaration of Helsinki, Guidelines for Good Pharmacoepidemiology Practices, and regulatory requirements.

\section{Patient Population}

The patient population analyzed in this study included children with GHD, Turner syndrome, Noonan syndrome, Prader-Willi syndrome, idiopathic short stature, or those born SGA, who were treated with GH as prescribed by the treating physician. Patients were classified into 1 of 3 main risk categories based on clinical diagnosis at the start of GH treatment and associated risk for long-term mortality (irrespective of GH treatment), as described previously $(12,15)$ and summarized in Table 1. If a patient had several diagnoses, categorization was based on the diagnosis belonging to the highest risk group. Patient classification into risk groups was carried out by the study sponsor and reviewed by 2 pediatric endocrinologists (authors L.S. and J.R.).

\section{Safety Evaluation}

Safety was evaluated on the basis of AEs reported by the treating physicians. Events reported prior to the GH treatment start were excluded from the analysis, as well as AEs reported after age 20 years.

Events evaluated in this analysis included (i) SAEs, (ii) AEs considered possibly/probably related to GH treatment, either by the reporting physician or the study sponsor (adverse drug reactions; ADRs), and (iii) serious ADRs
(SADRs). Nonserious and non-GH-related AEs were not included in this analysis, in line with the publication of interim data from the NordiNet IOS (16). AEs were considered serious if they resulted in death, a life-threatening experience, hospitalization or prolongation of existing hospitalization, a persistent or significant disability/incapacity, or were associated with a congenital anomaly/birth defect, or important medical events.

An overlap exists between the reported types of AEs. SADRs are a subset of SAEs that are considered related to GH treatment. Similarly, SADRs form a subgroup of ADRs, as ADRs include all nonserious and serious AEs related to GH treatment. Therefore, the total number of events reported in this analysis is the sum of SAEs and ADRs minus the number of SADRs.

All ADRs, SAEs, and SADRs were coded with the Medical Dictionary for Regulatory Activities terms (version 14.0) using system organ class (SOC) terminology. Incidence of events by SOC is reported for preferred-term events that occurred more than 10 times. Exceptions reported in more detail are (i) events of special interest, including neoplasms and cardiovascular events, and (ii) targeted AEs that occurred in previous studies, such as slipped capital femoral epiphysis (SCFE), increased intracranial pressure (ICP; diagnosed by lumbar puncture, computed tomography, or magnetic resonance imaging), edema, and headache $(6,8,19-21)$.

\section{Statistical Analysis}

All code for statistical analyses was written using the SAS 9.4 software. Baseline and exposure data were summarized using descriptive statistics. The overall duration of GH treatment was calculated for each patient in patientyears of exposure, from the date of first treatment to the

Table 1. Diagnoses at start of growth hormone treatment used for classification of patients into risk groups

\begin{tabular}{|c|c|c|}
\hline 1. Low-risk group & 2. Intermediate-risk group & 3. High-risk group \\
\hline A. Non-SGA subgroup & $\begin{array}{l}\text { Multiple pituitary hormone } \\
\text { deficiency }\end{array}$ & $\begin{array}{l}\text { All malignancies } \\
\text { Langerhans cell histiocytosis }\end{array}$ \\
\hline Isolated GHD & Severe cerebral malformation & After bone marrow or solid transplantation \\
\hline Idiopathic short stature & Short stature and severe & Chronic renal failure \\
\hline $\begin{array}{l}\text { Isolated GHD with a minor cranio- } \\
\text { facial malformation (eg, cleft lip) }\end{array}$ & $\begin{array}{l}\text { extracerebral malformation } \\
\text { Chromosomal anomalies, in- } \\
\text { cluding Turner syndrome } \\
\text { Clinically defined syndromes } \\
\text { Severe chronic pediatric disease }\end{array}$ & $\begin{array}{l}\text { Syndromes with known increased risk for malignancies (eg, Bloom, } \\
\text { Fanconi, Down, and chromosomal breakage syndromes) } \\
\text { Previously treated for cancer }\end{array}$ \\
\hline B. SGA subgroup & $\begin{array}{l}\text { Long-term steroid use in chronic } \\
\text { inflammatory disease }\end{array}$ & Craniopharyngioma \\
\hline Short stature in children born SGA & $\begin{array}{l}\text { Benign pituitary tumors } \\
\text { Cushing disease }\end{array}$ & \\
\hline
\end{tabular}


end of the treatment or the patient's last visit. The average $\mathrm{GH}$ dose up to the onset of the first $\mathrm{AE}$ was used instead of the average $\mathrm{GH}$ dose throughout the whole treatment period, for a more accurate analysis of the relationship between AEs and the GH dose. However, for a GH dose comparison between patient groups that did or did not experience AEs, the average GH dose throughout the treatment period was used for patients who did not experience any AEs. This comparison was carried out using the $t$ test, and the Satterthwaite approximation was used in the case of inequality of variances (22). Statistically significant differences in all analyses were defined as a $P$ value lower than .05 .

In each risk group and low-risk subgroup, patients were stratified into $3 \mathrm{GH}$ dose groups based on their average $\mathrm{GH}$ dose up to the first AE: 0 to 30, greater than 30 to 40, and greater than $40 \mu \mathrm{g} / \mathrm{kg} / \mathrm{day}$. Unlike the previous analysis of the NordiNet IOS (16), patients in dose groups 0 to 20 and greater than 20 to $30 \mu \mathrm{g} / \mathrm{kg} /$ day were pooled together because of the relatively low numbers of patients treated with a GH dose below $20 \mu \mathrm{g} / \mathrm{kg} /$ day.

Incidence rates of ADRs, SAEs, and SADRs were calculated as the number of events within the study period per 1000 patient-years of exposure for each risk group and each GH dose group. The incidence rates were compared among the risk groups and between the low-risk subgroups by Poisson regression (log-linear model). The relationship between average $\mathrm{GH}$ dose up to the first $\mathrm{AE}$ and the occurrence of ADRs, SAEs, and SADRs was analyzed using Poisson regression (log-linear model) with the mean $\mathrm{GH}$ dose up to the first $\mathrm{AE}$ as a continuous explanatory variable.

The incidence of AEs by the duration of follow-up was studied by calculating the proportion of patients experiencing a given type of $\mathrm{AE}$, in a given year, out of all patients exposed that year for the first 5 years of follow-up. The correlation between $\mathrm{AE}$ incidence and duration of $\mathrm{GH}$ treatment was analyzed with the Spearman rank-order correlation.

\section{Results}

\section{Patient Characteristics}

In total, 37702 patients received GH treatment during 130476 patient-years of exposure. There were 9873 $(26.2 \%)$ previously GH treated (nonnaive) children and $27740(73.8 \%)$ GH-naive children (Table 2). Of the 89 remaining patients with an undetermined history of $\mathrm{GH}$ treatment, only 1 had reported an AE.

The majority of patients $(25790 ; 68.4 \%)$ were classified into the low-risk group, while 10369 (27.5\%) and

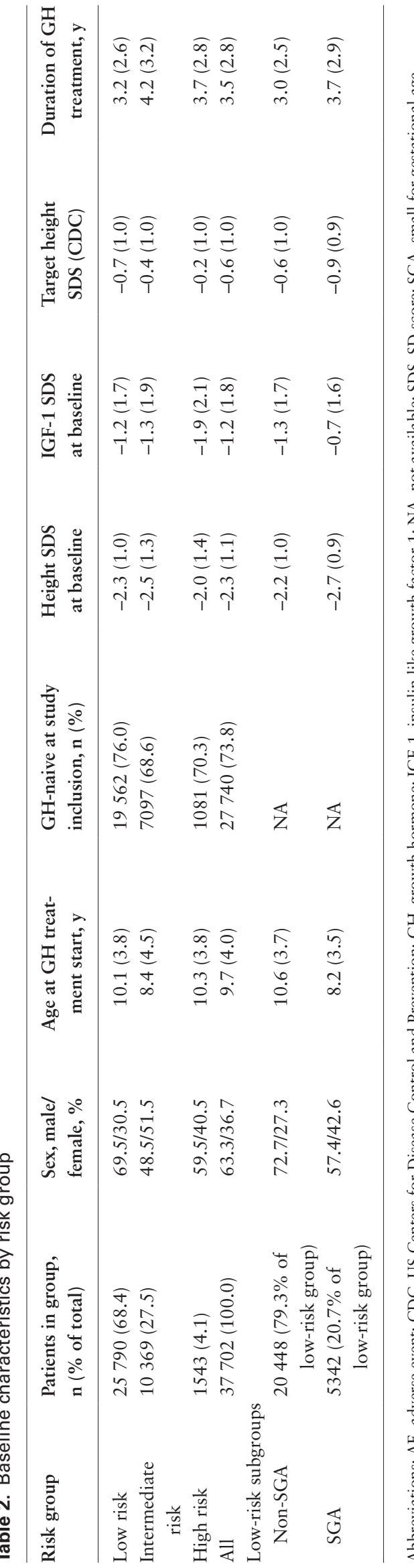


$1543(4.1 \%)$ were classified into the intermediate-risk and high-risk groups, respectively. Within the low-risk group, 20488 patients were classified as non-SGA and 5342 as SGA $(79.3 \%$ and $20.7 \%$ of the low-risk group, respectively).

General baseline characteristics of the patients have been published elsewhere (17). Baseline characteristics of patients grouped by risk category are summarized in Table 2. Overall, there were more boys than girls $(63.3 \%$ vs $36.7 \%$, respectively). The average age at treatment start was 9.7 years and average treatment duration 3.5 years. The intermediate-risk group was the only group with a majority of girls $(51.5 \%)$. However, without patients with Turner syndrome $(\mathrm{n}=2402 ; 23.2 \%$ of the intermediaterisk group), the sex ratio in the intermediate-risk group was $63.1 \%$ boys and $36.9 \%$ girls. Patients in the intermediaterisk group were on average younger at the start of treatment (8.4 years), with a lower baseline height SD score (SDS; -2.5 ) and longer duration of GH treatment (4.2 years) compared with the low- and high-risk groups.

Within the low-risk subgroups, on average, children born SGA started treatment earlier (age 8.2 years) with a lower height SDS $(-2.7)$ and were treated for a longer period (3.7 years) than the non-SGA patients (age 10.6 years, height SDS -2.2 and treatment duration 3.0 years).

\section{Growth Hormone Dose up to First Adverse Event}

Average and cumulative absolute $\mathrm{GH}$ doses and duration of GH treatment up to the onset of the first AE are summarized for each risk group in Table 3. The average $\mathrm{GH}$ dose prior to the first $\mathrm{AE}$ was significantly higher in the low-risk group than in the intermediate-risk group $(P=.013)$, and the dose both in the low- and intermediaterisk groups was significantly higher compared with that in the high-risk group $(P<.001$ for both). The average $\mathrm{GH}$ dose prior to the first AE did not differ significantly between the low-risk subgroups. Duration of GH treatment up to the first $\mathrm{AE}$ onset was longer in the intermediaterisk group ( 2.9 years) and similar in the low- and high-risk groups (2.4-2.5 years). Cumulative absolute dose prior to the first $\mathrm{AE}$ was higher in the low- and intermediate-risk groups (579-584 mg) compared with the high-risk group (543 mg) (see Table 3).

In the low-risk subgroups, $\mathrm{GH}$ dosing between the nonSGA and SGA patients appeared similar; however, nonSGA patients received a higher cumulative absolute GH dose compared with the SGA group.

Almost half of all patients $(49.8 \%)$ received an average $\mathrm{GH}$ dose of more than $40 \mu \mathrm{g} / \mathrm{kg} /$ day up to the first AE. The largest proportion of patients receiving such a dose was in the low-risk group (54.3\% of patients), particularly in the
non-SGA subgroup (57.4\% of the low-risk group). Only $28.6 \%$ of patients in the high-risk group received GH doses of more than $40 \mu \mathrm{g} / \mathrm{kg} /$ day (Table 4). The proportion of patients receiving a GH dose of 30 to $40 \mu \mathrm{g} / \mathrm{kg} /$ day before the first AE onset was similar across all risk groups $(28.7 \%$ $31.5 \%)$; however, this dose range was more prevalent in the SGA subgroup $(45.5 \%)$ compared with the non-SGA subgroup (27.8\% of the low-risk group) (see Table 4$)$.

The average GH dose in patients who did not experience any AEs, compared with patients who experienced at least one $\mathrm{AE}$, appeared higher in all 3 risk groups (Fig. 1A) and in the low-risk subgroups (Fig. 1B). This difference was significant in the low-risk group $(P<.001)$, intermediaterisk group $(P=.007)$ and in the non-SGA low-risk subgroup $(P<.001)$.

\section{Frequency and Incidence Rates of Adverse Events}

During the 2 studies, 849 patients $(2.3 \%)$ experienced 1242 AEs (Table 5). Among the risk groups, proportionally more patients experienced AEs in the high-risk group (107; $6.9 \%$ of the group) and the intermediate-risk group (361; $3.5 \%)$, compared with the low-risk group (381; $1.5 \%$ ). Within the low-risk group, a slightly higher proportion of the SGA patients experienced AEs (93; 1.7\%) compared with the non-SGA patients $(288 ; 1.4 \%)$. Among the types of AEs, ADRs were most prevalent in the low-risk group (particularly in the non-SGA subgroup, in which they represented $81.4 \%$ of events). SAEs occurred most frequently in the high-risk group ( $70 \%$ of events). SADRs comprised $190(15.3 \%)$ of all events and occurred at a similar rate across all groups.

Incidence rates (events per 1000 patient-years within the study period) were the lowest in the low-risk group (4.7 for ADRs, 2.3 for SAEs, and 0.9 for SADRs) and increased with each higher risk category (7.2 for ADRs, 8.1 for SAEs, and 2.1 for SADRs in the intermediate-risk group, and 13.9 for ADRs, 20.5 for SAEs, and 5.0 for SADRs in the high-risk group). These differences were statistically significant among all risk groups for all 3 event types $(P<.0001$ for all comparisons; Fig. 2A). For the low-risk subgroups, the incidence rate of ADRs was significantly higher in the non-SGA patients $(P=.05)$, whereas the incidence rate of SAEs was significantly higher in the SGA subgroup $(P=0.001)$ (Fig. 3A). The incidence rate of SADRs was not significantly different between these subgroups $(P=.472)$.

The incidence rates of ADRs, SAEs, and SADRs were also compared in subgroups of patients stratified into GH dose categories, based on average GH dose prior to the first $\mathrm{AE}$ onset. The patient distribution into $\mathrm{GH}$ dose groups is summarized in Table 4. When evaluating the mean GH 


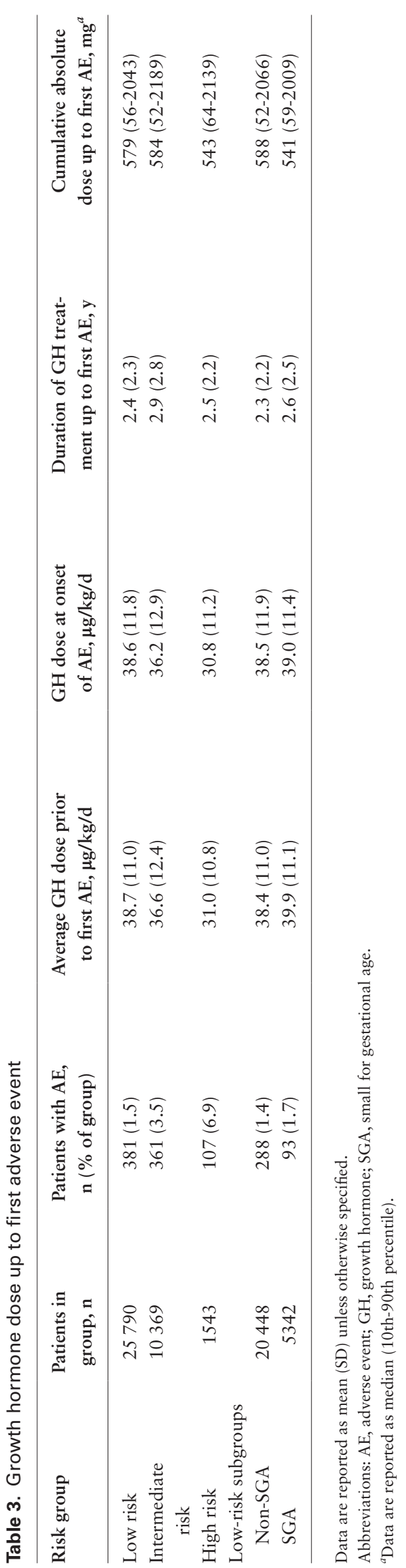

dose up to the first $\mathrm{AE}$ as a continuous variable, a significant inverse relationship with $\mathrm{GH}$ dose was shown for incidence rates of ADRs and SAEs in the low-risk group $(P=.003$ and $P=.001$, respectively) and for SAEs in the intermediate- and high-risk group $(P=.002$ and $P=.048$, respectively) (Fig. 2B). Within the low-risk group, an inverse relationship with $\mathrm{GH}$ dose was found for incidence rates of ADRs and SAEs in the non-SGA subgroup (both $P=.002$ ) (Fig. 3B).

Analysis of the annual incidence of AEs has shown that the proportion of patients experiencing ADRs, SAEs, and SADRs among all exposed patients remained relatively stable throughout 5 years of follow-up $(0.3 \%-0.6 \%$ for ADRs, $0.2 \%-0.3 \%$ for SAEs, and $0.0 \%-0.1 \%$ for SADRs; Fig. 4). There was a significant negative correlation between the occurrence of ADRs and the duration of GH treatment $(P=.037)$, whereas it was not significant for SAEs and SADRs $(P=.624$ and $P=.188$, respectively).

\section{Safety Profile}

Adverse events by system organ class and preferred term ADRs were most frequent among "nervous system disorders" (236 events), "musculoskeletal and connective tissue disorders" (228 events), and "general disorders and administration-site conditions" (104 events) (Fig. 5). The most common preferred-term ADRs were headache (205 events), arthralgia (92 events), scoliosis (42 events), and injection-site reaction (26 events).

SAEs were most frequent in "nervous system disorders" (123 events), "musculoskeletal and connective tissue disorders" (70 events), and "infections and infestations" (68 events) (see Fig. 5). The most common preferred-term SAEs were seizure (44 events), and SCFE and scoliosis (20 events each). Of the total 656 SAEs, 15 had a fatal outcome, details of which have been described previously (17). Among the low-risk subgroups, children born SGA were more likely to experience SAEs $(1.0 \%$ of patients in the subgroup) than non-SGA children $(0.2 \%$ of patients in the subgroup). This difference was most pronounced in "respiratory, thoracic, and mediastinal disorders" $(7.7 \%$ vs $0.8 \%$ of events in SGA and non-SGA groups, respectively) and "skin and subcutaneous tissue disorders" $(7.7 \%$ vs $1.6 \%$ of events). In non-SGA children, SAEs were more often reported in "psychiatric disorders" $(9.0 \%$ vs $0.0 \%$ of events in non-SGA and SGA groups, respectively) and "musculoskeletal and connective tissue disorders" $(17.2 \%$ vs $4.6 \%$ of events).

SADRs were overall most frequent in "musculoskeletal and connective tissue disorders" (47 events) and "nervous system disorders" (36 events) (see Fig. 5). The most 
Table 4. Number of patients and patient-years in growth hormone dose groups within each risk group and low-risk subgroups

\begin{tabular}{|c|c|c|c|}
\hline Risk group & $\mathrm{GH}$ dose group, $\mu \mathrm{g} / \mathrm{kg} / \mathrm{d}$ & Patients, $n$ ( $\%$ of risk group) & Patient-years \\
\hline \multirow[t]{3}{*}{ Low risk } & $0-30$ & $3617(14.2)$ & 13571 \\
\hline & $30-40$ & $8000(31.5)$ & 28799 \\
\hline & $>40$ & $13793(54.3)$ & 38240 \\
\hline \multirow[t]{3}{*}{ Intermediate risk } & $0-30$ & $2773(27.1)$ & 13187 \\
\hline & $30-40$ & $3167(31.0)$ & 13708 \\
\hline & $>40$ & $4280(41.9)$ & 16140 \\
\hline \multirow[t]{3}{*}{ High risk } & $0-30$ & $650(42.8)$ & 2811 \\
\hline & $30-40$ & $435(28.6)$ & 1658 \\
\hline & $>40$ & $434(28.6)$ & 1231 \\
\hline \multicolumn{4}{|c|}{ Low-risk subgroups } \\
\hline \multirow[t]{3}{*}{ Non-SGA } & $0-30$ & $2983(14.8)$ & 11391 \\
\hline & $30-40$ & $5597(27.8)$ & 19266 \\
\hline & $>40$ & $11553(57.4)$ & 30424 \\
\hline \multirow[t]{3}{*}{ SGA } & $0-30$ & $634(12.0)$ & 2179 \\
\hline & $30-40$ & $2403(45.5)$ & 9533 \\
\hline & $>40$ & $2240(42.4)$ & 7815 \\
\hline
\end{tabular}

Abbreviations: GH, growth hormone; SGA, small for gestational age.

common preferred-term SADRs were SCFE (18 events), headache, and increased ICP (12 events each).

\section{Vascular events in the low-risk group}

There were 2 cardiovascular events in 2 individual patients, both of whom made a recovery. One non-SGA patient experienced hypotension, an SAE considered possibly related to $\mathrm{GH}$ treatment. It occurred after 3.5 years of $\mathrm{GH}$ treatment with an average dose of $41.5 \mu \mathrm{g} / \mathrm{kg} /$ day. One SGA patient reported a hematoma on the left thigh (not serious and possibly GH-related) after 8.1 years of GH treatment with an average dose of $35.8 \mu \mathrm{g} / \mathrm{kg} /$ day. There were no cases of cerebral hemorrhage in any risk group.

\section{Neoplasms}

At baseline, 281 patients $(2.7 \%)$ in the intermediate-risk group and 868 patients $(56.3 \%)$ in the high-risk group had a medical history of a neoplasm before GH treatment initiation. Over the course of the study, 56 patients reported 62 neoplasms, of which $37(59.7 \%)$ were considered unlikely related to $\mathrm{GH}$ treatment, $22(35.5 \%)$ were possibly GH related, and 3 (4.8\%) were probably GH related. Details about the diagnoses and $\mathrm{GH}$ treatment of these 56 patients are summarized in Table S1 in the Supplementary Material (23).

Eight neoplasms in 8 patients $(0.03 \%)$ were reported in the low-risk group. Two of them $(0.04 \%)$ occurred in the SGA subgroup (benign oral neoplasm possibly GH related, and T-cell lymphoma unlikely GH related), and 6 $(0.03 \%)$ in the non-SGA subgroup (nephroblastoma and Langerhans cell histiocytosis unlikely to be GH related, benign juvenile melanoma and malignant mixed mesenchymal tumor possibly GH related, and melanocytic nevus and lipoma probably GH related). None of these patients had a prior history of a neoplasm.

In the intermediate-risk group, 22 neoplasms were reported in 21 patients $(0.20 \%)$, of which 14 were unlikely to be related to $\mathrm{GH}$ treatment, 7 possibly, and 1 probably $\mathrm{GH}$ related. Six of these patients had history of a neoplasm before starting GH treatment.

There were 32 neoplasms in 27 patients $(1.75 \%)$ in the high-risk group, of which 20 were considered unlikely to be related to $\mathrm{GH}$ treatment and 12 possibly related. Of the 27 patients, 25 had a history of a malignancy prior to $\mathrm{GH}$ treatment initiation. Four events had a fatal outcome (recurrent medulloblastoma unlikely to be related, primitive neuroectodermal tumor unlikely to be related, metastases to meninges possibly related, and acute myeloid leukemia unlikely to be related to the $\mathrm{GH}$ treatment). A single case of bone cancer (osteosarcoma in the occipital region) occurred in a 10-year-old girl after 5 years of GH treatment indicated for GHD, with an average dose of $38.6 \mu \mathrm{g} / \mathrm{kg} /$ day. The patient had a history of medulloblastoma diagnosed before the start of GH treatment. After the diagnosis of osteosarcoma, GH treatment was discontinued and the event was considered unlikely related to the treatment.

\section{Targeted adverse events}

There were 18 events both of edema and increased ICP, 21 events of SCFE, and 207 events of headache. Edema was the most common in the intermediate-risk group (12/18 events; 
$2.1 \%$ of all AEs in the risk group), whereas headache and increased ICP were the most common in the low-risk group (106/207 [21.3\%] and 10/18 [2.0\%], respectively). SCFE occurrence was the highest in the high-risk group (4/21 events; $2.4 \%$ of all AEs in the group). Among the low-risk subgroups, the occurrence of edema and increased ICP was higher in the non-SGA children compared with those SGA

(A)

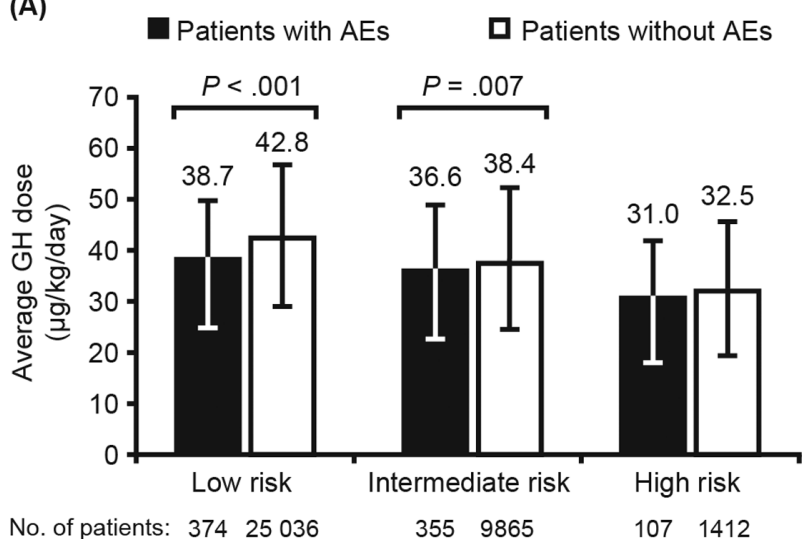

(B)
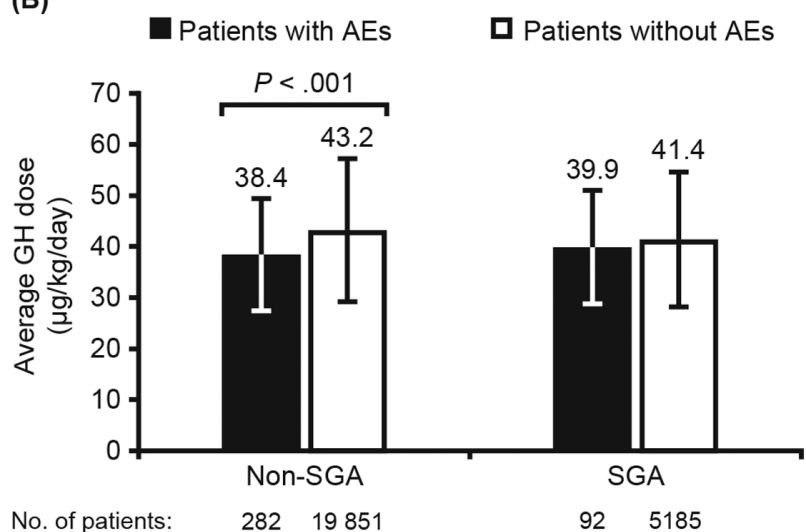

Figure 1. Comparison of average growth hormone dose between patients who did or did not experience at least one adverse event in $A$, risk groups and $\mathrm{B}$, low-risk subgroups. Only significant $P$ values $(<.05)$ are shown. For patients with $A E s$, average $G H$ dose up to the first $A E$ onset was used. For patients without AEs, average $\mathrm{GH}$ dose from the full treatment period was used. $A E$, adverse event; $G H$, growth hormone; SGA small for gestational age.
(5/5 and $8 / 10$ events, respectively $[1.3 \%$ and $2.1 \%$ of all AEs in the subgroup, respectively]). Headache occurred at a similar rate in both subgroups $(81 / 207[21.5 \%]$ in the non-SGA and 25/207 [20.7\%] in the SGA subgroup), as well as SCFE (6/8 [1.6\%] in the non-SGA and $2 / 8$ [1.7\%] in the SGA subgroup).

Patients experiencing any of the 4 targeted AEs received a higher mean GH dose at the AE onset (38.9-43.7 $\mu \mathrm{g} / \mathrm{kg} /$ day) compared with the whole patient population (30.8$38.6 \mu \mathrm{g} / \mathrm{kg} /$ day). The average duration of GH treatment up to the $\mathrm{AE}$ onset was shorter in patients experiencing increased ICP and edema (1.5 and 1.8 years, respectively) and similar for SCFE and headache (2.7 and 2.4 years, respectively), compared with the whole population for any AE (2.4-2.9 years). Diagnoses of the patients experiencing these targeted events, together with information about the duration of GH treatment and GH dose, are summarized in Table S2 in the Supplementary Material (23).

\section{Discussion}

This analysis of 2 large, noninterventional, real-world studies, the NordiNet IOS and ANSWER Program, provides valuable insight into the safety of GH treatment with 5 -year follow-up in clinical practice. No unexpected safety signals were observed, and the safety profile of GH treatment in this analysis was consistent with other observational studies reported previously $(8,24-26)$, including our preliminary analysis of data from the NordiNet IOS (16).

Analyses presented in this report were based on patients categorized into 3 risk groups to overcome the complication of analyzing a highly heterogeneous cohort with different preexisting risks. Indeed, we observed that the $\mathrm{AE}$ incidence rates within the study period correlated with increasing risk category for all 3 types of AE (Fig. 2A), as was the proportion of patients experiencing any AEs (see Table 3). However, the frequency of ADRs showed the opposite trend, as the proportion of ADRs declined with increased risk category (see Table 5). These observations are likely related to the inherent increased risk and seriousness of events associated with the underlying diagnoses of

Table 5. Frequency of adverse drug reactions, serious adverse events, and serious adverse drug reactions by risk group

\begin{tabular}{|c|c|c|c|c|c|}
\hline Risk group & Patients in group (n) & Patient-years & ADRs, n (\%) & SAEs, n (\%) & SADRs, n (\%) \\
\hline Low risk & 25790 & 81332 & $383(76.9)$ & $187(37.6)$ & $72(14.5)$ \\
\hline Intermediate risk & 10369 & 43385 & $311(54.3)$ & $351(61.3)$ & $89(15.5)$ \\
\hline High risk & 1543 & 5759 & $80(47.3)$ & $118(69.8)$ & $29(17.2)$ \\
\hline \multicolumn{6}{|c|}{ Low-risk subgroups } \\
\hline Non-SGA & 20448 & 61693 & $307(81.4)$ & $122(32.4)$ & $52(13.8)$ \\
\hline SGA & 5342 & 19639 & $76(62.8)$ & $65(53.7)$ & $20(16.5)$ \\
\hline
\end{tabular}

Abbreviations: ADR, adverse drug reaction; SADR, serious adverse drug reaction; SAE, serious adverse event; SGA, small for gestational age. 

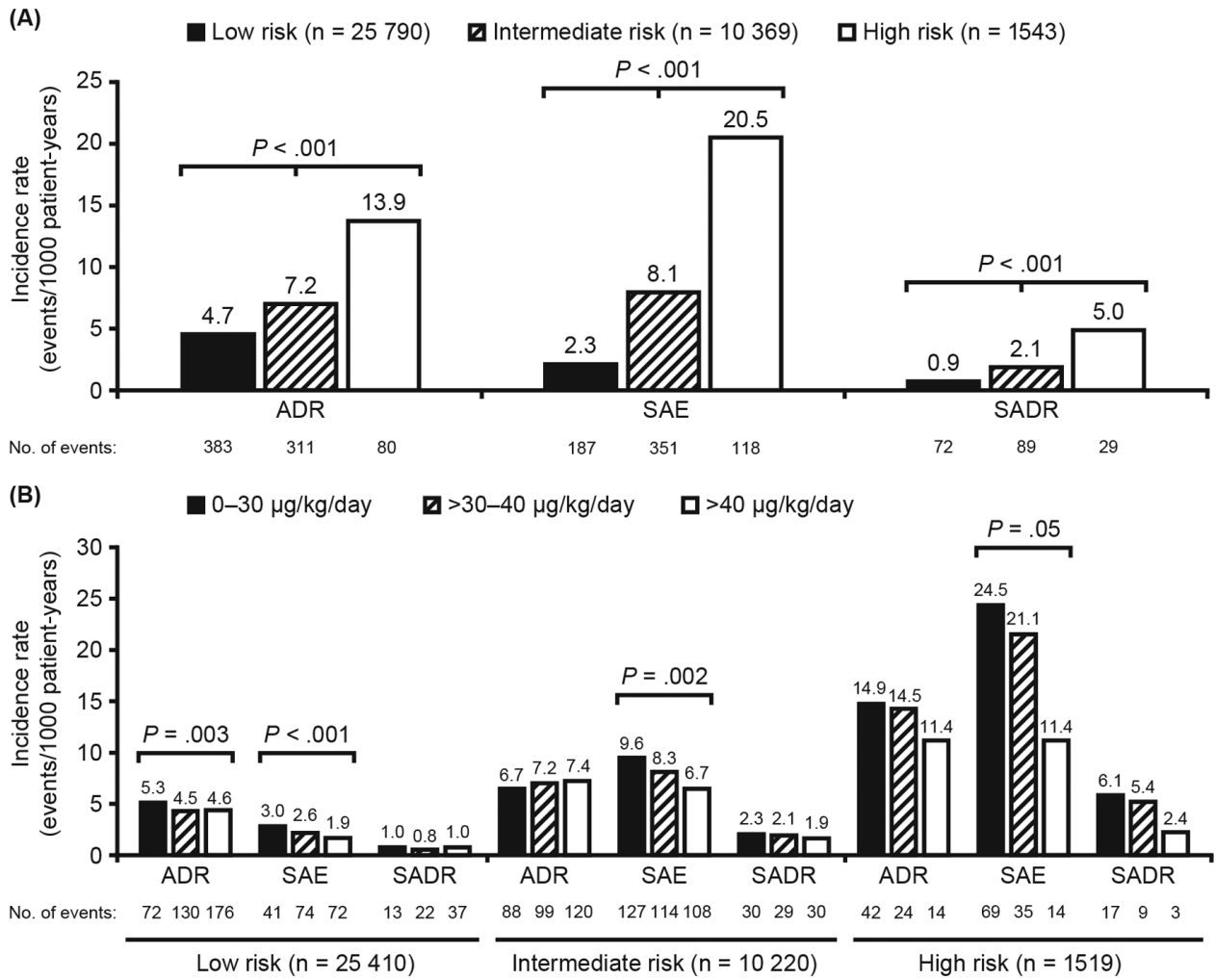

Figure 2. A, Incidence rates (events/1000 patient-years of exposure within the study period) for reported adverse drug reactions (ADRs), serious adverse events (SAEs), and serious adverse drug reactions (SADRs) by risk groups. B, Incidence rates for ADRs, SAEs, and SADRs by average growth hormone dose up to the first AE within each risk group. Only significant $P$ values $(<.05)$ are shown.

patients in the high-risk group (eg, chronic kidney disease and malignant tumors prior to GH treatment).

There was no evidence indicating an increased risk of experiencing AEs with increased GH dose. On the contrary, patients who experienced 1 or more AEs received a lower average GH dose up to the time of the $\mathrm{AE}$ onset, compared with the average dose for patients without any AEs. This result was consistent across risk groups and statistically significant in the low- and intermediate-risk groups and in the non-SGA low-risk subgroup (see Fig. 1). Similarly, we observed a significant decrease in incidence rates of ADRs and SAEs with the increasing average GH dose in the low-risk group (overall, and specifically in the non-SGA subgroup), and also in incidence rates of SAEs in the intermediate-and high-risk group. For the remaining groups and event types, the incidence of AEs appeared independent of the GH dose (see Fig. 2B).

The inverse relationship between $\mathrm{AE}$ incidence rates and GH dose may be partially explained by the practice of prescribing lower $\mathrm{GH}$ doses to patients who were overall more likely to experience AEs. This notion is supported by the decreasing mean $\mathrm{GH}$ dose at $\mathrm{AE}$ onset with the increasing risk category $(38.4,35.9$, and $30.9 \mu \mathrm{g} / \mathrm{kg} / \mathrm{day}$ in the low-, intermediate-, and high-risk groups, respectively). The relationship may also be partially driven by the higher likelihood of experiencing some treatment-related AEs (eg, edema or increased ICP $[8,27]$ ) in the early stage of GH treatment, while receiving a lower starting GH dose. Indeed, the proportion of patients experiencing ADRs was slightly elevated during the first year of GH treatment (see Fig. 4).

Within the low-risk group, incidence rates were significantly lower for ADRs, but significantly higher for SAEs in the SGA subgroup compared with the non-SGA subgroup. A similar pattern was observed in the previous analysis from NordiNet IOS (16). The frequency of SAEs among all AEs was 1.7-fold higher for SGA children compared with non-SGA children (see Table 5). However, the average GH dose prior to $\mathrm{AE}$ onset between these 2 groups was similar, despite a higher recommended dose for SGA $(35 \mu \mathrm{g} / \mathrm{kg} / \mathrm{day}$ in Europe and $\leq 67 \mu \mathrm{g} / \mathrm{kg} / \mathrm{day}$ in the United States) compared with the GHD indication $(25-35 \mu \mathrm{g} / \mathrm{kg} /$ day in Europe and $24-34 \mu \mathrm{g} / \mathrm{kg} / \mathrm{day}$ in the United States). The higher incidence of SAEs in children born SGA may be related to their intrinsic higher morbidity profile compared with peers born appropriate for gestational age $(28,29)$.

The mean duration of GH treatment up to the onset of the first $\mathrm{AE}$ was quite long (2.3-2.9 years across risk groups). The duration of $\mathrm{GH}$ treatment up to the first $\mathrm{AE}$, as well as the overall duration of GH treatment, was the 

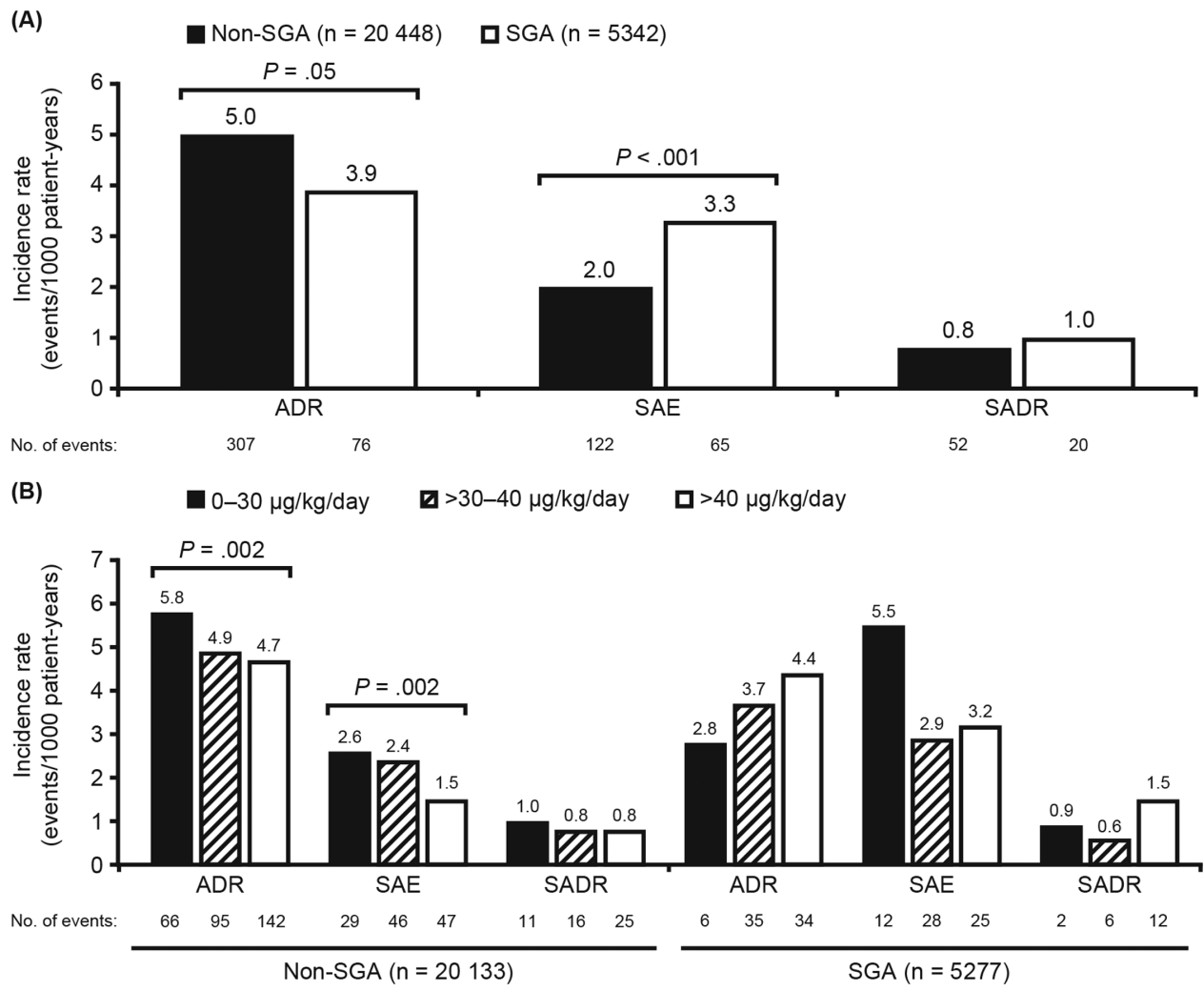

Figure 3. A, Incidence rates (events/1000 patient-years of exposure within the study period) for reported adverse drug reactions (ADRs), serious adverse events (SAEs), and serious adverse drug reactions (SADRs) in the low-risk group by subgroup (non-small for gestational age [SGA] vs SGA). B, Incidence rates for ADRs, SAEs, and SADRs by growth hormone dose up to the first AE in each subgroup. Only significant $P$ values $(<.05)$ are shown.

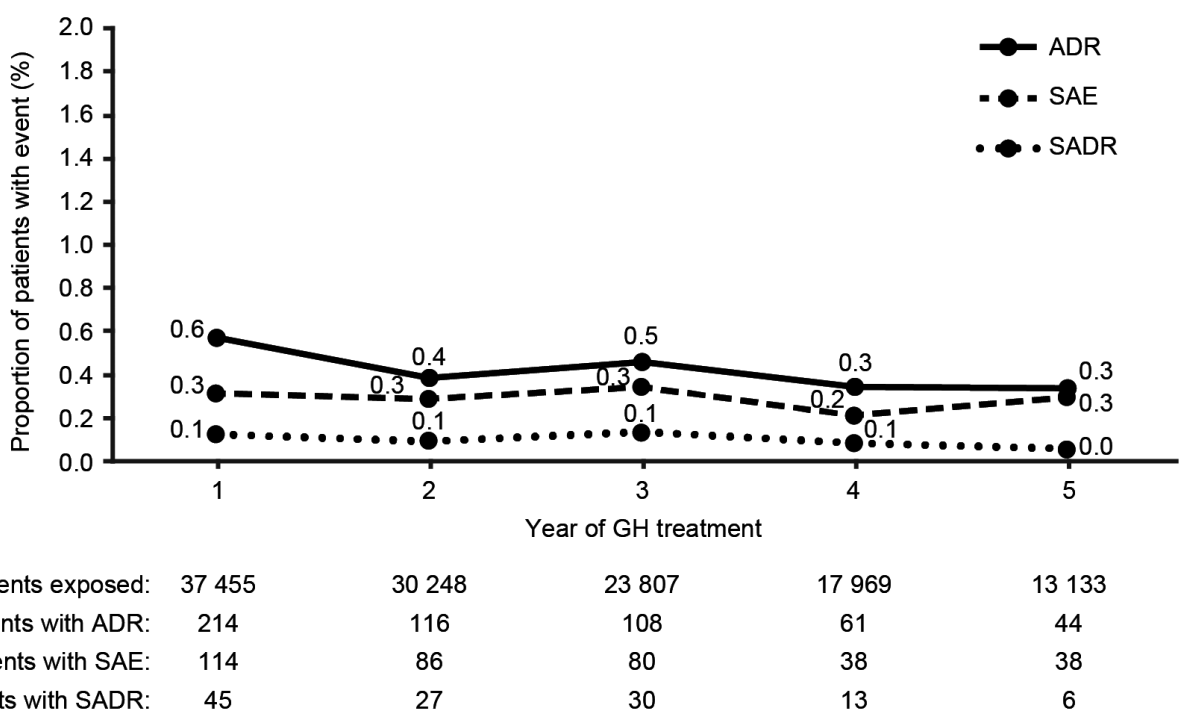

Figure 4. Proportion of patients with at least one adverse drug reaction (ADR), serious adverse event (SAE), or serious adverse drug reaction (SADR) of all patients exposed in a given year by duration of follow-up. GH, growth hormone.

longest in the intermediate-risk group. This could be partially explained by the relatively high proportion of patients with congenital conditions (eg, Turner syndrome), many of whom are diagnosed early in life. The proportion of patients experiencing AEs by year of follow-up remained quite stable throughout 5 years. This indicates that the likelihood of experiencing AEs was low and relatively consistent throughout the duration of GH treatment.

Of the 62 neoplasms reported in this study, most (52\%) were reported in the high-risk group. This was expected, as patients with an underlying history or risk for malignancy were included in the high-risk group, and the majority of 


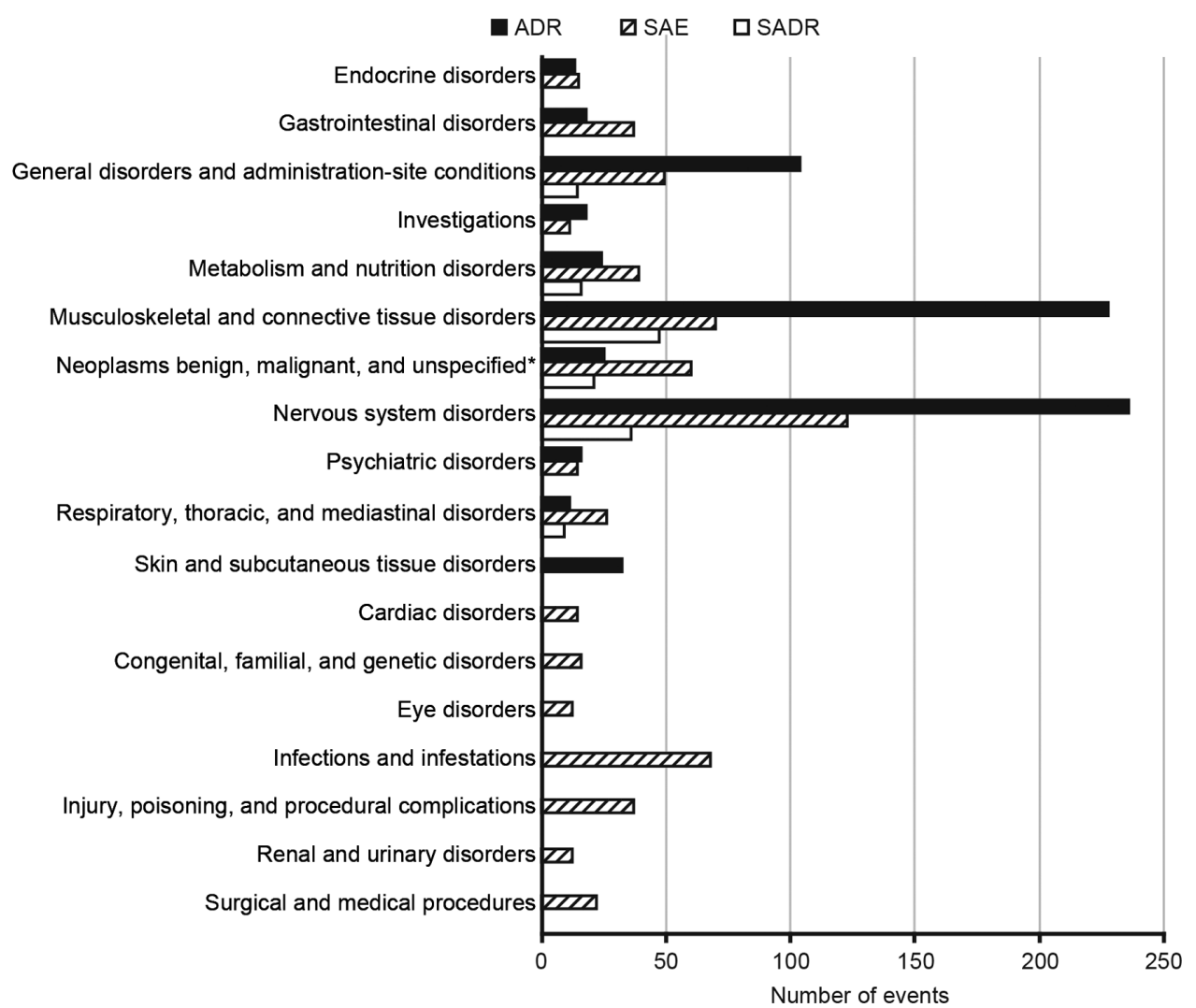

Figure 5. Frequency of adverse drug reactions (ADRs), serious adverse events (SAEs), and serious adverse drug reactions (SADRs) across all risk groups by system organ class (SOC). Only SOCs with more than 10 events are shown. *Including cysts and polyps.

the patients in this group (93\%) had a previous medical history of a neoplasm before the start of GH treatment. There was a single case of osteosarcoma throughout the duration of the 2 studies, and it occurred in the high-risk group. This is in contrast with the French SAGhE study, in which 5 of 6874 low-risk patients experienced bone or cartilage tumors (13). Additionally, there were no cases of cerebral hemorrhage in the low-risk group in our study, which contrasts with the 7-fold increased mortality ratio due to cerebrovascular diseases in the French SAGhE cohort (12). However, as was later shown for the full SAGhE population, the elevated mortality risk in the low-risk patients was driven mainly by the French SGA subcohort (15). In addition, our data report events occurring during GH treatment, whereas SAGhE analyzed events occurring in older individuals who received GH treatment as children.

The lack of follow-up beyond the cutoff age of 20 years likely limits the potential of our data to capture the risk of developing noncommunicable diseases (eg, diabetes, cardiovascular morbidity, or neurodegenerative diseases) in older age. The etiology of such diseases can originate as early as during intrauterine development and early childhood, and is thus influenced by factors beyond genetic predisposition, for example, environmental factors $(30,31)$. In a recent analysis of long-term risk of cardiovascular morbidity in Swedish patients treated with GH in childhood, the authors have partially accounted for this phenomenon (32). In addition to a long follow-up period of up to 25 years, each patient was matched with 15 control individuals from the general population matched for sex, birth year, and geographical region, and important covariates were included, such as birth characteristics and socioeconomic status (32). Capturing such a breadth of information is useful for retrospective analyses of long-term safety, as the baseline risk for noncommunicable diseases changes over time (33).

Among the 4 targeted AEs (SCFE, headache, increased ICP, and edema), only SCFE was the most common in the high-risk group. Notably, of the 21 cases of SCFE, 5 occurred in conditions with previously reported increased risk of SCFE (Turner syndrome, chronic renal insufficiency, and inflammatory bowel disease with presumed glucocorticoid treatment) (34-36). Patients experiencing SCFE also received a higher average GH dose up to the AE onset $(43.7 \mu \mathrm{g} / \mathrm{kg} /$ day $)$ compared with the whole patient population $(30.9-38.6 \mu \mathrm{g} / \mathrm{kg} / \mathrm{day})$, which may have contributed to the rapid height velocity associated with SCFE (34), or to acute joint changes. Edema and increased ICP are likely related to the water retention and 
temporary imbalance of cerebrospinal fluid production and resorption associated with GH treatment $(20,37)$, and thus possibly related to GH dose. Patients experiencing edema or ICP increase received a higher average GH dose $(39.0-39.8 \mu \mathrm{g} / \mathrm{kg} /$ day $)$ than the whole patient population, although this difference was less pronounced than in the patients with SCFE. It is possible that patients experiencing these targeted events had a relatively high sensitivity to GH. Given the possible link between the targeted events and GH dose, a gradual GH dose increase could be considered for future studies. Lastly, the patients who reported headache received similar average $\mathrm{GH}$ dose as patients in the low-risk group, which is where it was most frequently reported. Formulating hypotheses about the relationship between GH treatment and headache is limited by the low specificity of the symptom and the heterogeneity of concomitant diagnoses (Table S2 in the Supplementary Material [23]).

The strengths of our study lie in the pooling of data from 2 large observational studies with a similar design, which provide a greater number of cases for investigation of patient subgroups and infrequent events, as well as strengthening the statistical power of the data. The confidence in our findings is further underpinned by the methodical validation of data entry (18), systematic checking for outliers, and elimination of obvious data entry errors. The NordiNet IOS and the ANSWER Program were not constrained by a highly specific protocol, and offer an inclusive picture of the use and effectiveness of GH treatment in clinical practice.

Limitations of our study include the lack of an untreated control group, which limits the impact of drawing conclusions from the results. However, this is an inherent limitation of all noninterventional observational studies, and conducting a long-term randomized trial would be unfeasible and unethical. Given the multinational nature of our study, there is a potential for confounding of the results by local differences in diagnostics, laboratory analyses, and reporting of events among different clinics and countries, resulting in a potential lack of firm diagnoses in some patients. However, an earlier analysis of between-country reporting rates for AEs in the NordiNet IOS revealed no obvious differences (16). Limitations in the study design include data on AE-related discontinuations not systematically collected in either registry, and voluntary ascertainment that could introduce a bias and/or lead to incomplete data capture. Lastly, the patient cohort in the ANSWER Program had a large number of children with idiopathic short stature and isolated GHD. Because these groups have previously been shown to have fewer side effects (15), and the ANSWER Program cohort received higher GH doses in general (17), the relationship of higher doses to an increased incidence of AEs could be diluted. However, we have addressed this potential concern by categorizing the patients into relevant risk groups and subgroups.

In summary, we found no indication of increased risk of mortality or incidence of AEs related to GH dose in any risk group. Our findings support a favorable benefit-risk profile of GH treatment across the indications included in the NordiNet IOS and the ANSWER Program.

\section{Acknowledgments}

Financial Support: Statistical analyses were performed by Jean-Marc Ferran (Qualiance ApS), funded by Novo Nordisk Health Care AG. Medical writing and editing support was provided by Sonia Vyskocilova, PhD, and Beverly La Ferla, MRes, of Watermeadow Medical, part of the Ashfield Group, supported by Novo Nordisk Health Care AG. NordiNet IOS was designed by the sponsor, Novo Nordisk A/S. The ANSWER Program was designed by Novo Nordisk Inc.

Clinical Trial Information: NordiNet International Outcome Study (ClinicalTrials.gov registration No. NCT00960128) (registered April 1, 2006); ANSWER Program (ClinicalTrials.gov registration No. NCT01009905) (registered June 24, 2002).

Author Contributions: All authors were involved in conducting this study and data collection, drafting, critical revision, and final approval of the version of the paper to be published. All authors agree to be accountable for all aspects of the work. All authors affirm that the work submitted for publication is original and has not been published other than as an abstract or preprint in any language or format and has not been submitted elsewhere for print or electronic publication consideration.

\section{Additional Information}

Correspondence: Lars Sävendahl, MD, PhD, Karolinska University Hospital J9:30, Visionsgatan 4, SE-171 64, Solna, Sweden. Email: lars.savendahl@ki.se.

Disclosures: L.S. consults for Merck and Novo Nordisk, and has received lecture fees from Ascendis, Hexal, Merck, Novo Nordisk, and Pfizer. M.P. is employed by Université de Paris and Necker University Hospital; has served on boards for Novo Nordisk GNAP, Pfizer France, IPSEN European Increlex registry; and has received grants from Novo Nordisk, Pfizer, Ipsen, Sandoz, Merck, Sanofi, ANR, and PHRC. P.B. consults for Novo Nordisk, Ipsen, Ascendis, EndoPharmaceuticals and BioMarin; has received research funding from Ipsen, NovoNordisk, and Opko/Pfizer; and is a member of the board of directors or advisory committee(s) of the American Board of Pediatrics and Pediatric Endocrine Society. J.C.B. has received payment for membership of the publication steering committee of the NordiNet IOS, and previously as a member of the trial steering committee; has received financial support to attend scientific meetings; and has received honoraria for lectures. B.S.M. consults for Abbvie, Ascendis, BioMarin, Bluebird Bio, Endo Pharmaceuticals, Novo Nordisk, Orchard, Pfizer, Sandoz, Sanofi Genzyme, Tolmar, and Vertice; and has received research support from Abbvie, Alexion, Amgen, Amicus, Ascendis, BioMarin, Novo Nordisk, Opko, Protalix, Sandoz, Sangamo, Sanofi Genzyme, Tolmar, and Takeda. T.R.R. has acted as a consultant for Novo Nordisk and has received speaker 
honoraria from Novo Nordisk. A.H.-K. is employed by Erasmus University Medical Center, Rotterdam, the Netherlands; is a member of the Novo Nordisk Global Norditropin Advisory Panel; and has received independent research grants from Novo Nordisk and Pfizer for investigator-initiated and -responsible studies. A.P. is an employee of and holds stocks in Novo Nordisk. N.K. is employed by Novo Nordisk and has been employed by Pfizer within the last 2 years, and holds stocks in Pfizer and Novo Nordisk. J.R. is employed by Nemours duPont Hospital for Children; consults for Novo Nordisk and OPKO; has received research funding from Novo Nordisk; and is a member of the advisory committee of Novo Nordisk and OPKO.

Data Availability: Some or all data sets generated and/or analyzed during the present study are not publicly available but are available from the corresponding author on reasonable request.

\section{References}

1. Sävendahl L, Polak M, Backeljauw P, et al. Animated summary. Available at: https://nn-product.videomarketingplatform.co/secr et/67530345/7a3cb503b38861af9271afb41a3ac757

2. Pfäffle R, Land C, Schönau E, et al. Growth hormone treatment for short stature in the USA, Germany and France: 15 years of surveillance in the Genetics and Neuroendocrinology of Short-Stature International Study (GeNeSIS). Horm Res Paediatr. 2018;90(3):169-180.

3. Plotnick L, Rapaport R, Desrosiers P, Fuqua JS. Update from the GHMonitorSM observational registry in children treated with recombinant human growth hormone (Saizen). Pediatr Endocrinol Rev. 2009;6(Suppl 2):278-282.

4. Wyatt D. Lessons from the National Cooperative Growth Study. Eur J Endocrinol. 2004;151(Suppl 1):S55-S59.

5. Child CJ, Zimmermann AG, Chrousos GP, et al. Safety outcomes during pediatric $\mathrm{GH}$ therapy: final results from the prospective GeNeSIS observational program. J Clin Endocrinol Metab. 2019;104(2):379-389.

6. Pfäffle R, Bidlingmaier M, Kreitschmann-Andermahr I, et al. Safety and effectiveness of Omnitrope, a biosimilar recombinant human growth hormone: more than 10 years' experience from the PATRO Children study. Horm Res Paediatr. 2020;93(3):154-163.

7. Bell JJ, Lippe B, Romano AA, Cernich JT, Swinford RD, Moawad D. National Cooperative Growth Study: 25 years of growth hormone data, insights, and lessons for future registries. Pediatr Endocrinol Rev. 2018;16(2):240-255.

8. Bell J, Parker KL, Swinford RD, Hoffman AR, Maneatis T, Lippe B. Long-term safety of recombinant human growth hormone in children. J Clin Endocrinol Metab. 2010;95(1):167-177.

9. Bakker NE, Lindberg A, Heissler J, Wollmann HA, CamachoHübner C, Hokken-Koelega AC; KIGS Steering Committee. Growth hormone treatment in children with Prader-Willi syndrome: three years of longitudinal data in prepubertal children and adult height data from the KIGS database. J Clin Endocrinol Metab. 2017;102(5):1702-1711.

10. Bonfig W, Lindberg A, Carlsson M, et al. Efficacy of growth hormone treatment in children with type 1 diabetes mellitus and growth hormone deficiency-an analysis of KIGS data. J Pediatr. 2018;198:260-264.

11. Ranke MB, Lindberg A, Carlsson M, Camacho-Hübner C, Rooman R. Treatment with growth hormone in Noonan syndrome observed during 25 years of KIGS: near adult height and outcome prediction. Horm Res Paediatr. 2019;91(1):46-55.

12. Carel JC, Ecosse E, Landier F, et al. Long-term mortality after recombinant growth hormone treatment for isolated growth hormone deficiency or childhood short stature: preliminary report of the French SAGhE study. J Clin Endocrinol Metab. 2012;97(2):416-425.

13. Poidvin A, Touzé E, Ecosse E, et al. Growth hormone treatment for childhood short stature and risk of stroke in early adulthood. Neurology. 2014;83(9):780-786.

14. Sävendahl L, Maes M, Albertsson-Wikland K, et al. Long-term mortality and causes of death in isolated GHD, ISS, and SGA patients treated with recombinant growth hormone during childhood in Belgium, the Netherlands, and Sweden: preliminary report of 3 countries participating in the EU SAGhE study. J Clin Endocrinol Metab. 2012;97(2):E213-E217.

15. Sävendahl L, Cooke R, Tidblad A, et al. Long-term mortality after childhood growth hormone treatment: the SAGhE cohort study. Lancet Diabetes Endocrinol. 2020;8(8):683-692.

16. Sävendahl L, Pournara E, Pedersen BT, Blankenstein O. Is safety of childhood growth hormone therapy related to dose? Data from a large observational study. Eur J Endocrinol. 2016;174(5):681-691.

17. Sävendahl L, Polak M, Backeljauw P, et al. Treatment of children with GH in the United States and Europe: long-term follow-up from NordiNet IOS and ANSWER Program. J Clin Endocrinol Metab. 2019;104(10):4730-4742.

18. Höybye C, Sävendahl L, Christesen HT, et al. The NordiNet international outcome study and NovoNet ANSWER program: rationale, design, and methodology of two international pharmacoepidemiological registry-based studies monitoring long-term clinical and safety outcomes of growth hormone therapy (Norditropin). Clin Epidemiol. 2013;5:119-127.

19. Cowell CT, Dietsch S. Adverse events during growth hormone therapy. J Pediatr Endocrinol Metab. 1995;8(4):243-252.

20. Darendeliler F, Karagiannis G, Wilton P. Headache, idiopathic intracranial hypertension and slipped capital femoral epiphysis during growth hormone treatment: a safety update from the KIGS database. Horm Res. 2007;68(Suppl 5):41-47.

21. Souza FM, Collett-Solberg PF. Adverse effects of growth hormone replacement therapy in children. Arq Bras Endocrinol Metabol. 2011;55(8):559-565.

22. Satterthwaite FE. An approximate distribution of estimates of variance components. Biometrics. 1946;2(6):110-114.

23. Sävendahl L, Polak M, Backeljauw P, et al. Supplementary material for Long-term safety of growth hormone treatment in childhood: 2 large observational studies NordiNet IOS and ANSWER. 2021. Date of deposit: January 15, 2021. https://figshare.com/articles/journal_contribution/ Supplementary_material_for_Long-term_safety_of_growth_ hormone_treatment_in_childhood_Two_large_observational_ studies_NordiNet_IOS_and_ANSWER/13580342

24. Pfäffle R, Schwab KO, Marginean O, et al. Design of, and first data from, PATRO Children, a multicentre, noninterventional study of the long-term efficacy and safety of Omnitrope in children requiring growth hormone treatment. Ther Adv Endocrinol Metab. 2013;4(1):3-11.

25. Wilton P, Mattsson AF, Darendeliler F. Growth hormone treatment in children is not associated with an increase in the 
incidence of cancer: experience from KIGS (Pfizer International Growth Database). J Pediatr. 2010;157(2):265-270.

26. Mentser M, Breen TJ, Sullivan EK, Fine RN. Growthhormone treatment of renal transplant recipients: the National Cooperative Growth Study experience-a report of the National Cooperative Growth Study and the North American Pediatric Renal Transplant Cooperative Study. J Pediatr. 1997;131(1 Pt 2):S20-S24.

27. Critical evaluation of the safety of recombinant human growth hormone administration: statement from the Growth Hormone Research Society. I Clin Endocrinol Metab. 2001;86(5):1868-1870.

28. Saenger P, Czernichow P, Hughes I, Reiter EO. Small for gestational age: short stature and beyond. Endocr Rev. 2007;28(2):219-251.

29. Clayton PE, Cianfarani S, Czernichow P, Johannsson G, Rapaport R, Rogol A. Management of the child born small for gestational age through to adulthood: a consensus statement of the International Societies of Pediatric Endocrinology and the Growth Hormone Research Society. J Clin Endocrinol Metab. 2007;92(3):804-810.

30. Heindel JJ, Vandenberg LN. Developmental origins of health and disease: a paradigm for understanding disease cause and prevention. Curr Opin Pediatr. 2015;27(2):248-253.
31. Barker DJP. The origins of the developmental origins theory. $J$ Intern Med. 2007;261(5):412-417.

32. Tidblad A, Bottai M, Kieler H, Albertsson-Wikland K, Sävendahl L. Association of childhood growth hormone treatment with long-term cardiovascular morbidity. JAMA Pediatr. 2020;175(2):e205199.

33. Grimberg A. Cardiovascular disease in former pediatric recipients of growth hormone: another look at growth hormone safety. JAMA Pediatr. 2020;175(2):e205232.

34. Witbreuk M, van Kemenade FJ, van der Sluijs JA, Jansma EP, Rotteveel J, van Royen BJ. Slipped capital femoral epiphysis and its association with endocrine, metabolic and chronic diseases: a systematic review of the literature. J Child Orthop. 2013;7(3):213-223.

35. Loder RT, Hensinger RN. Slipped capital femoral epiphysis associated with renal failure osteodystrophy. J Pediatr Orthop. 1997;17(2):205-211.

36. Blethen SL, Rundle AC. Slipped capital femoral epiphysis in children treated with growth hormone. A summary of the National Cooperative Growth Study experience. Horm Res. 1996;46(3):113-116.

37. Obinata K, Kamata A, Kinoshita K, et al. Prolonged intracranial hypertension after recombinant growth hormone therapy due to impaired CSF absorption. Clin Pediatr Endocrinol. 2010;19(2):39-44. 